\title{
Classificações bibliográficas e classificações arquivísticas: diferenças e semelhanças na organização do conhecimento
}

\author{
Clasificaciones bibliotecarias y archivísticas: diferencias y semejanzas en la organización del conocimiento
}

Library classification and archive classification: diferences and similarities in knowledge organization

\section{Rodrigo de SALES}

Departamento de Ciência da Informação, Universidade Federal Fluminense, Niterói, Rio de Janeiro, Brasil, rodrigo.sales.s@gmail.com

\begin{abstract}
Resumen
En la bibliotecología y la archivística, las clasificaciones tienen características y funciones únicas. Este artículo analiza las clasificaciones de bibliotecas y archivos desde la perspectiva de la organización del conocimiento que proporcionan, con el fin de presentar y reflexionar sobre sus similitudes y diferencias. Se trata de una investigación eminentemente teórica que contextualiza estas clasificaciones en sus aspectos históricos y conceptuales con el fin de proporcionar un panorama comparativo entre ellos. Por lo tanto, su principal objetivo es poner de relieve las diferencias y similitudes entre ambas clasificaciones a través de un enfoque metodológico teórico y comparativo. Los resultados muestran que ambas clasificaciones son similares en cuanto a la naturaleza intelectual, los principios teóricos en los que se basan, los tipos de relaciones y la representación de conceptos. Sin embargo, son diferentes en lo que respecta a los tipos de conocimientos clasificados, los aspectos de los conceptos, los productos generados y los usos que se hacen de tales clasificaciones. Se concluye que, con el debido respeto a las similitudes y diferencias entre ambos tipos de clasificaciones, sin embargo, pueden y deben ser estudiadas juntas, unidas por los principios de la clasificación.
\end{abstract}

Palabras clave: Teoría de la clasificación. Clasificación. Clasificaciones bibliográficas. Clasificaciones archivísticas. Organización del conocimiento. Análisis comparativo.

Não sei se seria capaz de cumprir com a difícil tarefa de escrever um artigo que fizesse justa homenagem ao meu amigo Eduardo Murguia. Porém, certa vez, ele me pediu para escrever um texto que versasse sobre a organização do conhecimento contida nas classificações bibliográficas e arquivísticas, destacando suas semelhanças e diferenças. Penso que isso, eu posso fazer.

Para Eduardo Ismael Murguia (in memoriam)

\begin{abstract}
Among the several forms of knowledge organization, classification occupies a prominent position as it consists of one of the oldest ways of organizing knowledge. In Library and Archival Science, classifications have unique features and functions. This article discusses library and archival classifications from the perspective of the knowledge organization provided by these classifications, in order to present and reflect on their similarities and differences. It is an eminently theoretical research that contextualizes such classifications in their historical and conceptual aspects in order to provide a comparative scenario between them. Thus, its main objective is to highlight the differences and similarities between both classifications through a theoretical and comparative methodological approach. The results show that both classifications are similar with regard to the intellectual nature, the theoretical principles on which they are based, the kinds of relationships they support and the representation of concepts. However, they are different with regard to the types of classified knowledge, the aspects of concepts, the generated products and the uses that are made of them. We conclude that, once taken in account the similarities and differences between these types of classifications, they can and should be studied together, united by their classificatory principles.
\end{abstract}

Keywords: Classification theory. Classification. Bibliographic classifications. Archival classifications. Comparative analysis.

\section{Introdução}

A despeito das discussões sobre se a Biblioteconomia e a Arquivologia são disciplinas científicas, campos de estudo ou práticas profissionais, elas serão aqui abordadas como domínios. Na perspectiva epistemológica de Hjorland (2002), domínio consiste justamente nas discursividades que compõem a própria área, ou, no reflexo discursivo das coletividades que o concebem. Nesse sentido, Biblioteconomia e Arquivologia serão, do 
ponto de vista acadêmico, compreendidas como conjuntos discursivos.

A organização do conhecimento, enquanto espaço investigativo que se ocupa com as formas de se organizar e sistematizar o conhecimento, pode subsidiar as discussões tanto da Biblioteconomia quanto da Arquivologia, propiciando um efetivo espaço de interlocução entre os saberes de ambos os domínios. Neste artigo, a organização do conhecimento (OC) será abordada em seu aspecto instrumental, hoje abarcado pela denominação Sistemas de Organização do Conhecimento (SOC). Mais especificamente, o sistema de organização do conhecimento que será aqui abordado talvez seja o mais peculiar dos instrumentos da OC - a classificação.

Porém, há que se destacar o fato de que a organização do conhecimento, embora disponha de arcabouço teórico-metodológico capaz de ser experimentado nos mais variados domínios, está normalmente ligada às características do conhecimento a que se propõe organizar. Os tipos de conhecimentos organizados pela Biblioteconomia e pela Arquivologia, embora sejam domínios que encontrem no quesito informacional profícuo diálogo, distinguem-se fundamentalmente. Infere-se, destarte, que a organização do conhecimento promovida pelas classificações bibliográficas é distinta daquela promovida pelas classificações arquivísticas. Porém, se por um lado os conhecimentos organizados e sistematizados por ambas as classificações são distintos, por outro, $\mathrm{o}$ ato de classificar (formar classes) é essencialmente o mesmo.

Em uma dimensão abstrata, as classificações bibliográficas classificam assuntos e as classificações arquivísticas classificam ações. Sob uma perspectiva mais aplicada, o que pressupõe a materialização tanto dos assuntos quanto das ações, as classificações bibliográficas lidam com os documentos bibliográficos, ao passo que as classificações arquivísticas tratam os documentos arquivísticos.

Considera-se que os assuntos veiculados pelos documentos bibliográficos são aqueles próprios do conhecimento enciclopédico, como os assuntos da Física, da Biologia, da História, da Filosofia, da Engenharia etc., seja em um escopo universal ou em um escopo especializado. Isto é, as classificações bibliográficas podem ser sistemas de organização do conhecimento de abrangência universal, como a classificação de Dewey ou a classificação de Ranganathan ou, ainda, de abrangência especializada, como a Classificação Decimal do Direito. É importante ter clareza que o que se classifica nesses tipos de instrumentos são os assuntos do conhecimento enciclopédico.
Outra característica do documento de biblioteca é sua autonomia com relação aos demais documentos da coleção, ou melhor, seu valor unitário independentemente do contexto.

Já os documentos arquivísticos, cuja existência se refere às ações que os produziram, normalmente veiculam conhecimentos que dizem respeito às funções e atividades de uma entidade (pessoa ou instituição). Diferentemente das classificações bibliográficas, as classificações arquivísticas não podem ser universais em sua plenitude, pois os conhecimentos que elas organizam e classificam se referem à uma determinada entidade. Desse modo, enquanto as classificações de bibliotecas classificam assuntos enciclopédicos, as classificações elaboradas no âmbito arquivístico classificam as ações da entidade. Portanto, os conhecimentos que interessam a esses tipos de classificações são o funcionamento e a estrutura das entidades que produzem documentos. Para o presente estudo, concentra-se exclusivamente nas características das classificações funcionais, ou seja, aquelas elaboradas com base no funcionamento das entidades produtoras de documentos. Diferentemente dos documentos bibliográficos, os documentos arquivísticos completam e legitimam seu valor existencial quando contextualizados em um fundo arquivístico.

É pensando na organização do conhecimento proporcionada por esses dois tipos de classificações que o presente artigo tem como objetivo principal investigar as diferenças e semelhanças entre as classificações bibliográficas e as classificações arquivísticas. Para tanto, estabeleceuse os seguintes objetivos específicos: a) contextualizar a trajetória histórica de ambas as classificações; b) compreender a concepção estrutural e conceitual dessas classificações e; c) relacioná-las de forma comparativa.

Do ponto de vista metodológico, optou-se, primeiramente, pela pesquisa bibliográfica, que tornou possível identificar os elementos que efetivamente caracterizam ambas as classificações. Posteriormente, adotaram-se algumas variáveis referentes aos elementos característicos, de modo a possibilitar tanto a análise comparativa quanto a clareza na apresentação dos resultados.

\section{Marcos históricos e conceituais das classificações bibliográficas}

A história das classificações do conhecimento, no mundo ocidental, é tradicionalmente abordada pela literatura a partir das investidas filosóficas advindas da Antiguidade Clássica. Pensadores gregos deste período, que concebiam o 
mundo como um todo harmônico (onde os saberes estariam relacionados de tal forma que comporiam juntos um conhecimento universal), começaram a propagar a ideia de que a classificação do conhecimento se tratava de um exercício mental que dava lugar às coisas e às ideias que se tinham das coisas existentes. Para tanto, fazia-se necessário agrupar os saberes tanto em uma perspectiva mais abrangente, como na divisão das disciplinas realizada por Platão (Física, Ética e Lógica) e na divisão tripartitiva de Aristóteles (disciplinas teóricas, práticas e poéticas), quanto em uma perspectiva mais individualizante, como nas categorias fundamentais de Aristóteles (categorização do que pode se saber a respeito de um ente) e na árvore de Porfírio (consolidação da divisão dicotômica).

Embora fossem distintas as propostas de cada filósofo, por exemplo, enquanto Platão se ocupava com a organização do mundo abstrato das ideias, Aristóteles pretendia descrever o mundo sensível das coisas concretas, no legado de ambos os pensadores estão visíveis alguns elementos pioneiros na lógica classificatória.

Adentrando ao período Medieval, verifica-se que a classificação do conhecimento era fundamentalmente definida pelos currículos das universidades europeias, que exerceriam forte influência na classificação do conhecimento não somente da Idade Média, mas, também, nas classificações desenvolvidas na Idade Moderna. Segundo Burke (2003), os currículos medievais estavam estruturados em três grandes grupos de disciplinas: trivium, quadrivium e estudos superiores. $\mathrm{O}$ trivium era composto pelas chamadas ciências sermoniais (Gramática, Dialética e Retórica), responsáveis pelos conhecimentos relativos à linguagem. O quadrivium era constituído pelas denominadas ciências reais (Geometria, Aritmética, Astronomia e Música), convergentes aos estudos avançados relacionados aos números.

Tocante aos estudos superiores, as universidades contemplavam os cursos de Teologia, Direito e Medicina (Burke, 2003). Para Piedade (1983), as faculdades superiores deste período eram formadas por Teologia, Metafísica, Ética e História. Porém, como afirma Burke (2003), somente na Idade Moderna, a partir do século XVII, é que disciplinas relacionadas às humanidades ganharam espaço nos currículos europeus.

Do século XV ao século XVIII pensadores como A. Poliziano (1454-1494), M. Nizolio (14981556), J. Huarte (1535-1592), F. Bacon (15611626) e G. W. F. Hegel (1770-1831) empreenderam esforços para organizar os saberes de uma maneira fortemente influenciada pelo princípio de divisão tripartitivo de Aristóteles. Schreiner
(1979) destaca ainda Descartes (1596-1650), Hobbes (1599-1679), Locke (1632-1704), Leibnitz (1646-1715), Benthan (1748-1832), Ampère (1775-1836), Comte (1798-1857), Stuart Mill (1806-1873), Spencer (1820-1903) e Wundt (1832-1920), como autores de classificações que propunham uma ordem lógica para os conhecimentos, estabelecendo, assim, diferentes perspectivas classificatórias.

Mas foi a partir da segunda metade do século XIX que a classificação deixou de ser puramente científica ou filosófica, cuja função primordial era dar ordem lógica aos conhecimentos, para começar a desempenhar seu caráter mais aplicado de organização da informação, ou seja, dar ordem também aos conhecimentos materializados, servindo de base para a organização física de acervos de bibliotecas e a consequente localização dos itens bibliográficos.

Nos Estados Unidos, William Torrey Harris, Melvil Dewey e Charles Ammi Cutter, para citar alguns, começaram a investir esforços na organização sistemática dos assuntos existentes nos livros das bibliotecas. Concomitantemente, na Europa, Paul Otelt e Henri La Fontaine investiram na organização de informações bibliográficas de documentos das mais variadas naturezas.

Em 1870, o filósofo e educador norteamericano William Torrey Harris (1835-1909), responsável então pela rede de bibliotecas das escolas públicas de St. Louis (EUA), elaborou uma classificação bibliográfica que, com base na filosofia hegeliana, invertia a lógica da classificação filosófica definida por Francis Bacon, em 1605.

Bacon, pautado pelas faculdades mentais humanas, havia determinado a seguinte ordem para classificar os saberes: Memória (História), Imaginação (Poesia) e Razão (Filosofia). A classificação de Harris invertia a ordem das classes de conhecimento para: Razão (Ciências); Imaginação (Arte) e Registro (História). A classificação definida por Harris seria fundamental para a concepção do primeiro esquema de classificação bibliográfico de alcance reconhecidamente internacional, a Classificação Decimal de Dewey (Barbosa, 1969; Foskett, 1973; Piedade, 1983; Wiegand, 1996; Olson, 2011). O bibliotecário norteamericano Melvil Dewey (1851-1931) adotou a divisão de classes de assuntos definidas por Harris para delimitar suas divisões de assuntos principais.

Nas tabelas I e II, a seguir, verificam-se, respectivamente, a inversão realizada por Harris com relação à classificação de Bacon e como Dewey se inspirou nas classes de assuntos definidas por Harris para dar início ao seu sistema decimal. 


\begin{tabular}{|c|c|}
\hline Bacon (1605) & Harris (1870) \\
\hline HISTORY & SCIENCE \\
\hline Natural History & Philosophy \\
\hline Civil History & Theology \\
\hline \multirow[t]{6}{*}{ Appendix to History } & Social \& Political Sciences \\
\hline & Jurisprudence \\
\hline & Politics \\
\hline & Social Science \\
\hline & Philology \\
\hline & $\begin{array}{l}\text { Natural Sciences \& Useful Arts } \\
\text { Mathematics } \\
\text { Physics } \\
\text { Natural History } \\
\text { Medicine } \\
\text { Useful Arts and Trades }\end{array}$ \\
\hline $\begin{array}{l}\text { POETRY } \\
\text { Narratice or Heroic } \\
\text { Dramatic } \\
\text { Allegorical. Fables, } \\
\text { Mithologies }\end{array}$ & $\begin{array}{l}\text { ART } \\
\text { Fine Arts } \\
\text { Poetry } \\
\text { Prose Fiction } \\
\text { Literary Miscellany }\end{array}$ \\
\hline PHILOSOPHY & HISTORY \\
\hline $\begin{array}{l}\text { Theology or Divine } \\
\text { Philosophy }\end{array}$ & Geography and Travels \\
\hline Natural Philosophy & Civil History \\
\hline \multirow[t]{2}{*}{ Philosophy of Man } & Biography \\
\hline & APPENDIX Miscellany \\
\hline
\end{tabular}

Tabela I. Comparação entre as classificações de Bacon e Harris - Elaborado pelo autor, com base em Wiegand (1996) e Olson (2011)

\begin{tabular}{llll}
\hline Harris (1870) & \multicolumn{3}{l}{ Dewey (1876) } \\
\hline SCIENCE & 1 & $0-99$ & ------ \\
\hline Philosophy & $2-5$ & $100-199$ & Philosophy \\
\hline Theology & $6-16$ & $200-299$ & Theology \\
\hline Social \& Political Sciences & 17 & $300-399$ & Sociology \\
\hline Jurisprudence & $18-25$ & & \\
\hline Politics & $26-28$ & & \\
\hline Social Science & $29-31$ & & \\
\hline Philology & $32-34$ & $400-499$ & Philology \\
\hline Natural Sciences \& Useful & 35 & $500-599$ & Natural Science \\
Arts & & & \\
\hline Mathematics & $36-40$ & & \\
\hline Physics & $41-45$ & & \\
\hline Natural History & $46-51$ & & \\
\hline Medicine & $52-58$ & & \\
\hline Useful Arts and Trades & $59-63$ & $600-699$ & Useful Arts \\
\hline ART & 64 & & \\
\hline Fine Arts & 65 & $700-799$ & Fine Arts \\
\hline Poetry & $66-68$ & & \\
\hline Prose Fiction & $69-70$ & & \\
\hline Literary Miscellany & $71-78$ & $800-899$ & Literature \\
\hline HISTORY & 79 & $900-999$ & History \\
\hline Geography and Travels & $80-87$ & & \\
\hline Civil History & $88-96$ & & \\
\hline Biography & 97 & & \\
\hline Appendix Miscellany & $98-100$ & & \\
\hline & & & \\
\hline
\end{tabular}

Tabela II. Comparação entre as classificações de Harris e Dewey - Elaborado pelo autor, com base em Wiegand (1996) e Olson (2011)
Por se tratar de uma classificação desenvolvida por um filósofo, para fins de organização de acervos de bibliotecas, pode-se afirmar que a classificação de Harris marcou um período em que o universo das classificações bibliográficas se voltava também para as classificações filosóficas. Ranganathan (1967) afirmaria, no século XX, que toda classificação de biblioteca necessariamente consiste em uma classificação de assuntos, terreno historicamente explorado pela Filosofia. Embora tenha sido Harris o responsável pelo laborioso trabalho de classificar assuntos de livros com base em uma filosofia preestabelecida (filosofia de Hegel, neste caso), foi a classificação decimal desenvolvida por Dewey que logrou dimensão internacional, sobretudo para as bibliotecas ocidentais.

A notória convergência entre as classes de Dewey e de Harris - ambos iniciam com os saberes relacionados à razão e à cientificidade, passam pelos saberes relacionados à arte imaginativa $e$ chegam aos registros de memória - evidencia que o pioneirismo de Dewey não se configurou na definição de suas classes, pois Harris já havia antecipado esse desencadeamento lógico de assuntos.

A contribuição fundamental de Dewey estava, primeiramente, na definição de dez classes de assuntos principais, na subdivisão de cada uma das dez classes em dez subclasses e de cada subclasse em mais dez seções, o que proporcionava, minimamente, um arranjo sistemático de assuntos gradativamente mais específicos. A representação pragmática desses assuntos por meio de notações numéricas, pautadas em casas decimais, propiciou ao sistema de Dewey pontos fortes como: a) a localização relativa, pois antes de Dewey os livros das bibliotecas possuíam espaços físicos predeterminados, uma vez que a codificação era atribuída às estantes e não aos livros; b) a especificação detalhada de assuntos, pois os assuntos dos livros passaram a ser tratados com maiores detalhes, visto que agora possuíam maior mobilidade dentro dos acervos e dispunham de mecanismos notacionais que permitiam especificações, de assunto e de localização (Foskett, 1973). Por meio do código numérico decimal, Dewey proporcionou uma representação notacional clara e objetiva, pois a hierarquia dos assuntos era facilmente refletida pela hierarquia dos números que os representavam e, por conseguinte, o caráter mnemônico se tornava também possível com este tipo de notação.

No ano de 1876 , portanto, a primeira edição do sistema de Dewey era publicada anonimamente sob o título A Classification and Subject Index for Cataloguing and Arranging of Books and Pamphets of a Library. 
Criticando a notação decimal de Dewey, Charles Ammi Cutter (1837-1903) elaborou a chamada Expansive Classification (publicada entre $1891 \mathrm{e}$ 1893), que consistia em um sistema dividido em sete níveis de complexidade, sendo o primeiro nível mais básico (muito geral), o segundo menos geral, o terceiro menos ainda e assim sucessivamente até o nível sete, o mais detalhado. Objetivando um sistema de classificação que pudesse ser aplicado em bibliotecas e acervos dos mais variados tamanhos, de bibliotecas municipais a bibliotecas nacionais, Cutter intitulou seu sistema de Expansive Classification devido à possibilidade do sistema se expandir conforme o crescimento das coleções. Sua ideia era a aplicação do primeiro nível do sistema ao iniciar-se uma coleção, e na medida em que a coleção fosse crescendo seriam aplicados os níveis classificatórios mais elaborados.

Cutter considerava sua classificação como um sistema evolucionista, seguindo as ideias da História Natural, pois cada assunto, ou parte de assunto, era alocado em uma ordem que respeitava o aparecimento do respectivo assunto (e sua teoria) na natureza (Piedade, 1983). Assim, por exemplo, em Zoologia, a classificação de Cutter organizava-se dos protozoários aos primatas. As classes principais da classificação de Cutter podem ser observadas detalhadamente em Sayers (1955), Barbosa (1969) e Piedade (1983).

A Classificação Expansiva influenciou diretamente o desenvolvimento da Classificação da $\mathrm{Li}$ brary of Congress (LC), sobretudo na definição das classes principais, que seguem, em parte, a ordem da classificação de Cutter (Mills, 1960; Barbosa, 1969; Foskett, 1973; Maltby, 1975; Piedade, 1983; Coates, 1988). A Classificação da Library of Congress (LC) é a mais importante classificação utilitarista que se tem notícia, ou seja, uma classificação desenvolvida a partir das necessidades da própria coleção da biblioteca do congresso e sem bases científicas ou filosóficas no que diz respeito ao encadeamento de assuntos e organização lógica (Barbosa, 1969; Foskett, 1973; Maltby, 1975; Piedade, 1983). A característica de expansão conforme o crescimento do acervo foi mantido na classificação da LC.

Nos anos que se seguiram, especialmente no século $X X$, surgiram inúmeros sistemas que contribuíram para a história das classificações bibliográficas no ocidente, tais como a Classificação Decimal Universal (1905), a Subject Classification de James D. Brown (1906), a Colon Classification de S. R. Ranganathan (1933), a Bibliographic Classification de Henry E. Bliss (1940), as classificações especializadas desenvolvidas pelos integrantes do Classification Research Group (a partir de 1952) e os trabalhos desempenhados no âmbito da International Society for Knowledge Organization (a partir de 1989). Dentre os citados, dois sistemas ocupam lugar de destaque na história das classificações, a Classificação Decimal Universal, idealizada por Otlet e La Fontaine e a Colon Classification, criada por Ranganathan.

Em 1905, a partir da criação da Classificação Decimal Universal (CDU), desenvolvida por Paul Otlet (1868-1944) e Henri La Fontaine (18531843) no âmbito do Institut International de Bibliographie (IIB), o universo das classificações bibliográficas alcançou uma cientificidade decorrente de uma praxe profissional que transbordava os limites das bibliotecas e dialogava com as especificidades organizacionais dos centros de documentação. A CDU, baseada na classificação de Dewey, era um sistema hierárquico que, devido ao emprego de sinais gráficos, já esboçava uma tentativa de classificação em facetas, que surgiria conscientemente apenas com a Classificação de Dois Pontos de Ranganathan (Sales, 2014). A maior articulação proporcionada pelos dispositivos sintagmáticos para traduzir linguagem natural por meio de notações fez da CDU o primeiro sistema de classificação a viabilizar a síntese de dois ou mais assuntos de classes distintas. Com suas divisões de classes principais e subdivisões derivadas da CDD, a CDU avança a classificação de Dewey ao adotar em suas notações sistemas semióticos que cumpriam funções distintas de relacionamento entre os assuntos. Além de seguir a característica decimal preconizada por Dewey, as notações da CDU podiam (e podem) ser formadas por números, letras, símbolos gregos, marcas de pontuação, ou ainda a combinação de todos.

A partir da década de 1930, o universo da classificação de assuntos se transforma e alcança uma nova abordagem por meio do desenvolvimento daquela que pode ser considerada a grande teoria da classificação do século $X X$ - a Teoria da Classificação Facetada. Definida pelo matemático e bibliotecário indiano Shiyali Ramamrita Ranganathan (1892-1972), a respectiva teoria foi desenvolvida, aprimorada e aplicada ao longo de cerca de quarenta anos, concomitantemente ao desenvolvimento e aprimoramento de seu esquema de classificação facetada, a Colon Classification.

Baseada no agrupamento de assuntos que apresentam as mesmas características e os mesmos tipos de relacionamentos, Ranganathan ampliou a visão existente até então relativa aos sistemas de classificação mais difundidos, que se pautavam na relação de conhecimento mais geral para conhecimento mais específico, centrando atenção também em outros tipos possíveis de relações entre conceitos, como por exemplo: partes 
de um todo, propriedade-possuidor, ação-paciente ou agente etc. Preocupado com as partes que efetivamente formavam os assuntos compostos, Ranganathan desenvolveu um novo método para se classificar/indexar livros por assunto, pautando-se nas facetas que agrupavam (reuniam) esses componentes formadores de assuntos compostos e complexos (Barbosa, 1969, 1972; Foskett, 1973; Piedade, 1983; Sales, 2014).

Embora Ranganathan tenha escrito cerca de cinquenta livros e 1.500 artigos a respeito dos mais diversos campos da Biblioteconomia, sua teoria da classificação foi fundamentalmente abordada nos livros: Colon Classification, Prolegomena to Library Classification, Classification: fundamental and procedure, Classified Catalogue Code e, Headings and Canons (Piedade, 1983; Campos, 2001). De fato, Ranganathan foi o primeiro dentre os classificacionistas de bibliotecas a se preocupar em deixar seu legado teórico por meio de inúmeras publicações que objetivavam explicar e instrumentalizar estudiosos a respeito de seu sistema e sua teoria. No âmbito das classificações de assunto, a Teoria da Classificação Facetada despontou como um novo modo de pensar e fazer. Mais que um instrumento de classificação, tratava-se de um novo método de classificar.

Se o século XIX foi marcado pelas classificações bibliográficas desenvolvidas no âmbito das bibliotecas norteamericanas, e o século XX testemunhou o aprofundamento teórico-metodológico das classificações de assunto, o século $X X I$ vem refletindo, aplicando, experimentando e aprimorando as concepções já existentes, de modo a fomentar a criação de novas formas, técnicas e teorias para a classificação de assuntos. Suportadas por aparatos tecnológicos cada vez mais avançados, as pesquisas desenvolvidas, especialmente, pelos membros da International Society for Knowledge Organization (ISKO), vem criando meios para aprofundar e mais bem fundamentar os sistemas de organização do conhecimento, nome genérico dado à categoria de instrumentos no qual se inserem as classificações de assunto que, nas últimas, não ocupam mais apenas os espaços convencionais de informação (como as bibliotecas tradicionais).

Quaisquer que sejam as abordagens metodológicas e as conjunturas históricas sob as quais as classificações bibliográficas vêm sendo estudadas, a literatura tradicionalmente as definem como estrutura de conceitos agrupados em classes de assuntos semelhantes, de acordo com suas caraterísticas, relacionados hierárquica e associativamente, e representados por uma notação classificatória (síntese de símbolos) que serve tanto à organização das coleções de documentos por assunto, quanto à recuperação, também por assunto, de tais documentos (Barbosa, 1969; Foskett, 1973; Langridge, 1977; Dahlberg; 1979; Vickery, 1980; Kaula, 1984; Piedade, 1983; Gomes, 1996).

Nota-se, assim, alguns traços essenciais que caracterizam as classificações utilizadas nas bibliotecas. Primeiro, o fato de que as classificações decorrem do processo intelectual de relacionar conceitos de assuntos de acordo com suas características e formar estruturas classificadas de conceituais. O segundo traço característico, de ordem mais prática, é o de que as classificações bibliográficas tradicionalmente cumprem o duplo papel de formalizar tanto a ordem conceitual dos assuntos, que auxilia na busca por informações, quanto à ordem física em que os documentos foram organizados, auxiliando a recuperação da informação. As classificações bibliográficas são utilizadas, portanto, para o arranjo sistemático conceitual e físico dos acervos bibliográficos e funcionam como elos que ligam a busca e a recuperação da informação.

Segundo Barbosa (1969), Vickery (1980) e Piedade (1983), os conceitos de assuntos podem ser relacionados em uma classificação bibliográfica de maneira hierárquica (gênero/espécie e todo/parte) ou não-hierárquica (associativa). Um exemplo de uma relação hierárquica gênero/espécie pode ser observado na relação entre os conceitos meio de transporte - meio de transporte motorizado - automóvel. Uma relação hierárquica todo/parte é flagrante na ligação entre os conceitos membros superiores - membros inferiores - cabeça - tronco com relação ao termo corpo humano. Uma relação do tipo associativa (não-hierárquica) pode ser exemplificada por meio dos termos medicina - doença, pois ambos os termos, embora não estejam relacionados hierarquicamente um ao outro, guardam nítida relação semântica.

Pode-se, ainda, trabalhar com relações do tipo coordenada (relação horizontal), onde os conceitos estão em mesmo nível na hierarquia (como, por exemplo a relação dos conceitos automóvel motocicleta - ônibus sob o termo genérico meio de transporte motorizado) ou, ainda, relações do tipo subordinada (relação vertical), onde os conceitos se submetem uns aos outros de acordo com o número de características que possuem (como, por exemplo, na relação entre os termos mamífero-felino-leão). Para Ranganathan (1967), as relações coordenadas formam os renques, ao passo que as subordinadas formam as cadeias de conceitos. 
Todas as classificações mencionadas até então, desenvolvidas por Harris, Dewey, Cutter, Otlet, Ranganathan (este último avançou significativamente as possibilidades de relações entre conceitos), ou demais classificações bibliográficas que se tem notícia, de uma maneira ou de outra, lançam mão destes princípios classificatórios para definir e estruturar seus esquemas. Sem exceção, todas elas com a finalidade de organizar acervos bibliográficos por assunto.

\section{Contextualizando histórica e conceitualmente as classificações arquivísticas}

A história das classificações arquivísticas, assim como das classificações bibliográfica, também pode ser contada a partir da Antiguidade, pois, segundo Schellenberg (2002) e Silva et al. 1999, assim que a história do homem passou a ser registrada em documentos, surgiu a necessidade de organizá-los para acessa-los. Se de maneira ainda intuitiva e primitiva, o fato é que os conteúdos das atividades registradas em documentos já necessitavam ser acessados pelo homem, o que pressupunha, obviamente, algum tipo de organização. Embora a classificação seja uma genuína forma de organização, o que se permite inferir já haver classificação naquele período, a literatura começa a documentar suas práticas séculos mais tarde (Héon, 1999), especificamente na Europa dos séculos XVI e XVII (Duranti, 1997).

Ainda que as ações que produziam documentos fossem já base de métodos de ordenação a partir do século $\mathrm{XVI}$, especificamente nos agrupamentos documentais propostos por Jacob von Rammingen, segundo Duranti (1997), somente no século XVII o conceito de classificação desponta na Arquivologia por meio dos manuais normativos. Neste contexto, a autora destaca a obra $D e R e$ Diplomática, de Jean Mabillon, datada em 1681, onde é possível encontrar um método para investigar possíveis fatos e eventos em que os documentos se inserem.

Ao traçar uma trajetória para o conceito de classificação na Arquivologia, Sousa (2006) dividiu a história das classificações de documentos arquivísticos em dois grandes períodos: da Antiguidade até o século XIX e do século XIX até os dias atuais. Tal divisão se deve ao surgimento de princípios teóricos definidos no século XIX que buscavam uma prática arquivística mais objetiva. Muito provavelmente, Sousa $(2006 ; 2007)$ estabeleceu esta divisão histórica inspirado não somente pela literatura arquivística, mas também pela divisão proposta por Dahlberg (1979) entre a classificação enquanto arte, de base puramente intuitiva, e a classificação enquanto ciência, baseada em princípios teóricos.

Autores como Schellenberg (2002), Rousseau e Couture (1998), Silva et al. (1999), Cruz Mundet (2001) convergem ao relatar que os documentos de arquivos em períodos anteriores ao século XIX eram, salvaguardadas raras exceções, classificados de maneira intuitiva e ideológica, tomando por base aspectos temporários, geográficos, tipológicos e temáticos. Eram classificados com bases metódicas privilegiando a ordenação cronológica (Sousa, 2006). O cenário revelava, portanto, a ausência de princípios teóricos gerais que norteassem a prática de classificação nos arquivos.

Com os ideais iluministas fortemente propagados pela Revolução Francesa no final do século XVIII, nasceu uma nova concepção de soberania nacional, que perseguia, dentre outras coisas, a consolidação da igualdade, inclusive no que se referia à informação das atividades da administração pública. Neste contexto a Europa vê surgir o conceito de arquivo nacional, iniciado em 1789 com a fundação dos Archives Nationales na França.

Grosso modo, o arquivo nacional centralizava a guarda de toda documentação acumulada (produzida ou recolhida) pela administração pública, pois era uma maneira de viabilizar o acesso público e igualitário dos documentos que registravam as ações de interesse nacional. Porém, com a centralização da guarda dos documentos, surgiu um problema significativamente caro às pretensões da Arquivologia, a perda da memória da documentação pública, uma vez que os documentos, vindos das mais diversas origens (fontes), eram subjetivamente guardados em um único arquivo central, confundindo, assim, os fundos arquivísticos.

Em meados do século XIX, o arquivista e historiador francês Natalis de Wally, no âmbito dos Arquivos Departamentais do Ministério de Interior da França, publicou uma circular, datada em 24 de abril de 1841 , determinando que todos os documentos da administração pública deveriam ser reunidos por fundos, ou seja, os documentos deveriam ser agrupados de acordo com a sua proveniência. Assim, despontava uma noção de fundo arquivístico que se propagaria por toda a Europa, em que fundo se trataria do conjunto de documentos acumulados por uma mesma fonte (um estabelecimento, uma família, um indivíduo etc.). Com a referida circular, Natalis de Wally deu origem ao primeiro fundamento teórico da Arquivologia - o princípio de respeito aos fundos (Cruz Mundet, 2001; Schellenberg, 2002; Sousa, 2006 e 2007). 
Porém, mesmo respeitadas as proveniências dos fundos arquivísticos, a organização (e a classificação) interna dos arquivos continuava sendo realizada com bases metódicas, temáticas, topográficas e cronológicas, ao longo de toda a Europa. Somente quarenta anos mais tarde, em 1881, o diretor dos Arquivos de Estado da Prússia, H. von Seybel, por meio de regulamentação enunciou um novo princípio - o princípio de respeito à ordem original dos documentos. Este princípio determinava que era necessário respeitar a ordem em que os documentos eram acumulados pelas entidades. A ideia era que, além de se respeitar os fundos fosse respeitado também a ordem de acumulação deste fundo. Desta maneira, resolver-se-ia tanto o problema de organização externa quanto de arranjo interno dos documentos de arquivo. A união de ambos os princípios, respeito aos fundos e respeito à ordem original, daria corpo ao chamado princípio de proveniência (Cruz Mundet, 2001).

Uma das obras que certamente impulsionaram a divulgação do princípio de proveniência por toda comunidade arquivística foi o Manual dos Arquivistas Holandeses (Handleiding voor het ordenen em beschrijven van archivem), publicado por Muller, Feith e Friun em 1898. Nesta obra, que consistia, grosso modo, na delimitação de regras para descrição e arranjo em arquivos, o princípio de proveniência era tido como o norteador teórico para a arquivologia moderna.

Há de se ressaltar que, embora o princípio de proveniência fosse uma tentativa de alcançar maior objetividade na prática arquivística internacional, somente em países de tradição anglo-saxônicas, a contemplação do respeito à ordem original era possível, uma vez que no âmbito de suas atividades administrativas havia a função do registratur, responsável por registrar (codificar) o documento no momento em que o mesmo era acumulado pela entidade. Em países de tradição latina, como o Brasil, onde a função do registratur não é comum, a reprodução da ordem original dos documentos fica impraticável. Desse modo, em países de tradição latina, por exemplo, o princípio de proveniência não pode ser contemplado em sua plenitude.

Independentemente da viabilização ou não do princípio de proveniência em um âmbito internacional mais amplo, o fato é que a partir da criação deste princípio teórico (consolidado no século XIX, mas adotado predominantemente no século $\mathrm{XX}$ ) a organização de arquivo e, consequentemente, a classificação arquivística iniciaram um fazer mais objetivo e menos intuitivo, buscando cientificidade discursiva.
Para discorrer a respeito das classificações arquivísticas é importante esclarecer que o conceito de classificação na Arquivologia, está longe de um consenso internacional. Conforme afirma Sousa (2006), não somente no que se refere à classificação, mas em todo discurso arquivístico, verificasse diferenças terminológicas decorrentes de diferentes escolas arquivísticas que, por vezes, podem ocasionar confusões conceituais.

A perspectiva norteamericana de Schellenberg, que, a partir da década de 1950, aproximou os estudos arquivísticos da administração pública moderna, voltada mais aos valores administrativo e jurídico do documento de arquivo, consolidou a distinção dos fazeres profissionais pautado nas diferentes idades dos documentos provenientes da atividade administrativa. Nesta vertente, despontaria a distinção entre os arquivos correntes, preocupados com a documentação em seu contexto de produção e, os arquivos permanentes, voltados, por sua vez, para o contexto de custódia. Esta configuração para os documentos de arquivo fez surgir a distinção entre classificação e arranjo, onde o primeiro dizia respeito à organização dos documentos nos arquivos correntes e o segundo à organização dos documentos nos arquivos permanentes. Schellenberg (2002) justificava esta distinção afirmando que a utilização da documentação em contexto corrente era significativamente diferente do uso que se aplicava aos documentos em contexto de custódia. Dessa forma, surgiria no contexto americano também a distinção entre o gestor de documentos, profissional do arquivo corrente, e o arquivista, profissional dos arquivos permanentes (Cruz Mundet, 2001).

Esta perspectiva seria, sobretudo na década de 1990, contestada pela perspectiva da arquivística integrada, especialmente entre os canadenses. Nesta vertente de arquivística integrada, onde o foco está voltado para as atividades intelectuais e práticas da organização de arquivos independentemente da idade no ciclo documental, a distinção entre classificação e arranjo não faz o menor sentido, uma vez que, não importa se o documento tem 3 ou 30 anos de idade, o fato é que ele foi acumulado por uma dada entidade em decorrência da mesma ação que o gerou. Assim, a classificação, enquanto instrumento que define a ordem conceitual dos documentos com base em seu contexto de acumulação, serve ao arquivo independentemente da idade.

Outras divergências com relação ao conceito de classificação se referem à abrangência dada ao termo, que variam de tradições de diferentes idiomas. Por exemplo, enquanto a tradição espanhola adota os termos classificación, ordenación 
e instalación para designar três operações distintas, em outros idiomas, como em italiano, ordinamento, em francês, classement e, em inglês, arrangement, são termos que englobam tanto a classificação quanto à ordenação da tradição espanhola (Esteban Navarro, 1995).

Porém, a despeito das diferentes perspectivas, tradições e idiomas, algumas características parecem consenso quanto ao conceito de classificação arquivística do tipo funcional. A primeira dessas características diz respeito ao fato de que a classificação de arquivo é um instrumento resultante de uma atividade intelectual que visa dar ordem conceitual aos documentos de um fundo arquivístico. A segunda se refere ao fato que esta ordem deve ser pautada no contexto de produção dos documentos, ou seja, deve representar o contexto em que os documentos foram acumulados. A terceira característica, associada à demais citadas acima, refere-se ao fato de que a representação do contexto de produção deve se basear nas ações de diversos níveis (funções, subfunções, atividades, subatividades, atos etc.) que produzem ou acumulam documentos. Outro consenso é a afirmação de que o resultado da atividade de classificação se materializa em um instrumento denominado código ou plano de classificação. É possível encontrar também na literatura a expressão quadro de classificação. No exemplo abaixo, observa-se uma adaptação extraída do Plano de Classificação de Documentos da Administração Pública do Estado de São Paulo: Atividades-Meio.

\begin{tabular}{lll}
\hline Função: & 01 & ORGANIZAÇÃo ADMINISTRATIVA \\
\hline Subfunção: & 01.01 & Ordenamento jurídico \\
\hline Atividade: & 01.01 .01 & Elaboração de atos normativos \\
\hline Documento: & 01.01 .01 .01 & $\begin{array}{l}\text { Decreto, estatuto, código, regulamente, regimento, instrução normativa, norma, } \\
\text { resolução, deliberação, portaria. }\end{array}$ \\
\hline Atividade: & 01.01 .02 & Habilitação jurídica e regulamentação fiscal dos órgãos, entidades e empresas \\
\hline Documentos: & 01.01 .02 .01 & Alvará de funcionamento \\
\hline & 01.01 .02 .02 & Certificado de matrícula no Cadastro Específico do INSS - CEI \\
\hline 01.01 .02 .03 & $\begin{array}{l}\text { Comprovante de atualização de dados no Cadastro Nacional do Trabalhador - } \\
\text { CNT }\end{array}$ \\
\hline & 01.01 .02 .04 & $\begin{array}{l}\text { Comprovante de inscrição e de situação cadastral no Cadastro Nacional de } \\
\text { Pessoa Jurídica - CNPJ }\end{array}$ \\
\hline & 01.01 .02 .05 & Comprovante de inscrição no Cadastro de Contribuinte Mobiliário - CCM \\
\hline
\end{tabular}

Tabela III. Recorte da Classificação da SAESP (SAESP, 2016)

Nota-se, no exemplo acima, que os códigos atribuídos às ações que geram documentos estão desdobrados em três níveis de ações (Função, Subfunção e Atividade), até se chegar ao código do documento propriamente dito, que por sua vez, reflete as ações sob as quais o mesmo está subordinado. É possível observar, também, que a exemplo das codificações próprias das classificações de bibliotecas, a especificidade dos números aumenta de acordo com a especificidade das ações, refletindo, assim, a própria hierarquia das ações. Os códigos atribuídos aos documentos refletem esta hierarquia.

Diante do exposto até então, convergindo com a definição de Sousa (2006, p. 139), entende-se classificação arquivística como "atividade intelectual de construção de instrumentos para a organização dos documentos, independentemente da idade à qual eles pertençam".

\section{Classificações bibliográficas e classificações arquivísticas: uma comparação}

Os conhecimentos organizados e sistematizados nas classificações bibliográficas e arquivísticas, conforme foi apresentado na introdução deste artigo, são diferentes. O conhecimento organizado pelas classificações bibliográficas é o conhecimento enciclopédico e seus assuntos, ao passo que o conhecimento organizado pelas classificações arquivísticas são o funcionamento e a estrutura de uma entidade. Por ora, concentra-se notadamente nas classificações funcionais, que buscam representar o funcionamento de uma entidade produtora de fundo arquivístico. Cabe, então, investigar a concepção propriamente dita dessas classificações, sua dimensão de elaboração, os elementos que as compõem, suas relações, seus escopos, suas representações e resultados, bem como suas utilizações. 
No que se refere à elaboração desses instrumentos, em ambos os casos, biblioteconômico e arquivístico, as classificações são resultados de atividades eminentemente intelectuais que visam à formação de classes de elementos, que se fundamentam em princípios classificatórios para hierarquizar e relacionar seus elementos/termos. Os princípios classificatórios, próprios da teoria da classificação, correspondem normalmente à: a) relação de subordinação, que formam cadeias de termos subordinados uns aos outros. Essas relações, também conhecidas como hierárquicas, podem ser do tipo gênero/espécie e todo/parte e; b) relação coordenada, onde os termos estão relacionados em mesmo nível em uma estrutura hierárquica. Essas relações, também conhecidas como não-hierárquica, são do tipo associativas, relações que guardam alguma ligação semântica entre os termos.

Relativo aos termos, ou elementos que as compõem, as classificações bibliográficas se distinguem das arquivísticas. Ao passo que as primeiras são compostas por termos que designam conceitos de assuntos (enciclopédicos), as segundas são compostas por termos que correspondem a ações (pessoais ou institucionais). A hierarquia e o relacionamento formalizados em uma classificação bibliográfica refletem uma sistematização de assuntos, enquanto a hierarquia e o relacionamento definidos em uma classificação arquivística refletem uma sistematização de ações. Isto é, enquanto em uma classificação de biblioteca são definidas as relações dos assuntos mais genéricos e mais específicos, ou associados semanticamente, em uma classificação de arquivo são estabelecidas as relações das ações mais genéricas e mais específicas, bem como as ações associadas administrativamente.
Quanto às formas de representação dos termos, ambas as classificações se aproximam, pois, seja a representação de um assunto (nas classificações bibliográficas) ou a representação de uma ação (nas classificações arquivísticas) os termos sempre são designados por um código de classificação. Assim como o assunto Biografia é designado pelo código 97 na classificação de Harris (ver Tabela II), a atividade Elaboração de atos normativos é designada pelo código 01.01.01 na classificação da SAESP (ver Tabela III). A representação por meio de códigos ou notações também é um princípio classificatório, e zela pela não ambiguidade do termo representado.

O resultado de uma classificação bibliográfica é um sistema de classificação (também chamado pela literatura biblioteconômica de esquema ou tabela de classificação) que proporciona um arranjo sistemático de assuntos. O resultado de uma classificação arquivística é um plano de classificação (também conhecido pela literatura arquivística como código ou quadro de classificação) que proporciona um arranjo sistemático de ações.

Uma diferença marcante entre ambas as classificações está relacionada aos usos empregados a esses instrumentos. Enquanto os sistemas de classificação são empregados nas bibliotecas para a organização temática de catálogos de busca e para a localização (recuperação) temática dos documentos, os planos de classificação são utilizados nos arquivos para representar o contexto de produção dos documentos. Ou seja, enquanto as primeiras funcionam como elo que liga a busca e a recuperação da informação por assunto, as segundas funcionam como instrumentos que permitem compreender como o fundo arquivístico foi concebido.

\begin{tabular}{lll}
\hline Variáveis & Classificações Bibliográficas & Classificações Arquivísticas \\
\hline Concepção & Atividade intelectual de formação de classes & Atividade intelectual de formação de classes \\
\hline Conhecimento organizado & Enciclopédico & Pessoal ou institucional \\
\hline Princípios teóricos & Teoria da classificação & Teoria da classificação \\
\hline Elementos/termos & Designam assuntos & Designam ações \\
\hline Relações & Subordinadas (gênero/espécie e todo/parte) & Subordinadas (gênero/espécie e todo/parte) \\
\hline Representação & Coordenadas (associativas) & Coordenadas (associativas) \\
\hline Resultados & Códigos classificatórios & Códigos classificatórios \\
\hline Uso & Sistema de classificação & Plano de classificação \\
\hline
\end{tabular}

Quadro I. Comparação entre as classificações bibliográficas e arquivísticas 
Se os códigos das classificações bibliográficas informam onde o documento está, os códigos das classificações arquivísticas informam de onde o documento veio. Em ambiente arquivístico a recuperação de documentos é realizada por meio dos instrumentos de busca, tais como guias, inventários, catálogos e índices. Desse modo, é possível sintetizar tais observações por meio de um quadro que compare as variáveis em ambas as classificações.

Observa-se, no quadro acima, que das oito variáveis analisadas, quatro (50\%) apresentam se- melhanças entre as classificações e outras quatro $(50 \%)$ apresentam diferenças. No que diz respeito à concepção, aos princípios teóricos, às relações entre termos e à representação dos mesmos, tanto a classificação bibliográfica quanto a arquivística apresentam as mesmas características. Já, no que se refere ao conhecimento organizado, às correspondências dos termos, aos resultados e usos das classificações, ambas apresentaram características distintas.

Assim, pode-se visualizar as semelhanças e diferenças entre ambas as classificações da seguinte forma:

\begin{tabular}{|c|c|}
\hline Semelhanças & Diferenças \\
\hline $\begin{array}{l}\text { São frutos da mesma atividade intelectual (formação de } \\
\text { classes de elementos de mesma característica) }\end{array}$ & \multirow{3}{*}{$\begin{array}{l}\text { Diferentes tipos de conhecimentos são organizados por } \\
\text { ambas as classificações (bibliográficas: conhecimento } \\
\text { enciclopédico; arquivísticas: conhecimento pessoal e } \\
\text { institucional) }\end{array}$} \\
\hline Baseiam-se em princípios da teoria da classificação & \\
\hline Relacionam seus termos de forma subordinada & \\
\hline $\begin{array}{l}\text { (gênero/espécie e todo/parte) e coordenada } \\
\text { (associativas) }\end{array}$ & $\begin{array}{l}\text { Os termos designam aspectos diferentes do } \\
\text { conhecimento (bibliográficas: assuntos; arquivísticas: } \\
\text { ações) }\end{array}$ \\
\hline \multirow[t]{2}{*}{$\begin{array}{l}\text { Representam os termos por meio de códigos } \\
\text { classificatórios }\end{array}$} & $\begin{array}{l}\text { açoes) } \\
\text { Os instrumentos resultantes são distintos e com } \\
\text { propósitos distintos (bibliográficas: sistemas de } \\
\text { classificação; arquivísticas: planos de classificação) }\end{array}$ \\
\hline & $\begin{array}{l}\text { O uso que se faz dos instrumentos de classificação } \\
\text { (bibliográficas: organização de coleções e catálogos e } \\
\text { localização da informação; arquivísticas: representação } \\
\text { do contexto de produção da informação) }\end{array}$ \\
\hline
\end{tabular}

Quadro II. Semelhanças e diferenças entre as classificações bibliográficas e arquivísticas

Por fim, constata-se que as classificações arquivísticas se assemelham às classificações bibliográficas nos seguintes aspectos: ambas são construídas por meio da atividade intelectual de formação de classes; ambas as classificações lançam mão de princípios definidos pela teoria da classificação; tanto a classificação de biblioteca quanto a de arquivo relacionam seus termos de maneira subordinada e coordenada, atendendo aos princípios classificatórios e; representam seus termos por meio de códigos classificatórios. Por outro lado, cabe ressaltar que essas classificações se distinguem nos seguintes aspectos: nos tipos de conhecimentos que pretendem organizar (as bibliográficas organizam assuntos enciclopédicos, enquanto as arquivísticas organizam ações que produzem documentos); os termos formalizados pelas classificações bibliográficas representam conceitos de assuntos, ao passo que os termos relacionados nas classificações arquivísticas representam ações (funções e atividades); os instrumentos resultantes das atividades de classificação em bibliotecas e arquivos são distintos e com propósitos e usos diferentes, pois, os instrumentos bibliográficos são utilizados tanto para a organização quanto para a recuperação temático de documentos, ao passo que os arquivísticos são utilizados para a compreensão do contexto que formou o próprio fundo arquivístico. Cabe, enfim, salientar que esta investigação se limitou à classificação arquivística do tipo funcional.

\section{Conclusões}

Os aspectos aqui apresentados, que aproximam e também distanciam as classificações bibliográficas das classificações arquivísticas, servem como elementos que fortalecem a ideia de que, sob a perspectiva da organização do conhecimento, é perfeitamente possível estudar e explorar os potenciais de ambas as classificações sob diferentes pontos de vista. A separação que tradicionalmente de faz nos estudos e no ensino das classificações, seja no âmbito arquivístico ou biblioteconômico, normalmente fragmenta o entendimento desses sistemas que se nutrem pelos mesmos princípios teóricos - aqueles voltados ao ato de classificar. 
Uma das tentativas deste artigo foi mostrar que, respeitadas as peculiaridades de cada domínio e de cada fazer profissional, não por acaso trabaIharam-se aqui as diferenças e as semelhanças, é plausível, do ponto de vista científico, que a pesquisa e o ensino das classificações sejam amparados também pelos princípios teóricos que os sustentam, e não exclusivamente pelas ambiências que as utilizam. A cientificidade do discurso, especialmente do discurso das classificações, reside justamente no pensamento que busca refletir sobre princípios potencialmente generalizáveis, e não na utilidade isolada de instrumentos específicos.

Pesquisar e lecionar sobre classificações, enquanto instrumentos de organização do conhecimento, é entender a classificação como um saber próprio e autônomo, que pode ser empregado ora para os fins biblioteconômicos, ora para os fins arquivísticos. Desperdiçar este fio-condutor que une classificações bibliográficas e classificações arquivísticas pode potencializar demasiadamente a especialização das práticas em detrimento da ampliação dos horizontes teóricos. Aliás, talvez, entender a classificação com um saber autônomo, possa ajudar a questionar essa já ultrapassada separação entre a prática e a teoria. Essa aproximação entre ambas as classificações pode crescer exponencialmente quando a discussão for direcionada ao desterritorializado meio digital, porém, isso seria assunto para um outro artigo.

\section{Agradecimentos}

Agradecimento especial a Francisco Javier García Marco, editor da Revista Scire, que sensivelmente cedeu esta edição para a especial homenagem a Eduardo Murguia. Ao amigo e interlocutor Eduardo, obrigado por tudo!

\section{Referências}

Aristóteles (2010). Categorias. 2 ed. Tradução de José Veríssimo Teixeira da Mata. São Paulo: Martin Claret, 2010. ISBN978-85-7232-579-0.

Barbosa, A. P. (1969). Teoria e prática dos sistemas de classificação bibliográfica. Rio de Janeiro: Instituto Brasileiro de Bibliografia e Documentação, 1969. 441 p. (Obras Didáticas; 1).

Burke, P. (2003). Uma história social do conhecimento: de Gutenberg a Diderot. Tradução de Plínio Dentzien. Rio de Janeiro: Jorge Zahar, 2003. ISBN 85-7110-711-4.

Campos, M. L. A. (2001). Linguagem documentária: teorias que fundamentam sua elaboração. Rio de Janeiro: Eduff, 2001. ISBN85-228-03-19.

Coates, E. J. (1988). Subject catagues: headings and structure. London: The Library Association, 1988. ISBN 085365-678-9.

Cruz Mundet, J. R. (2008). Manual de archivística. 7.ed. Madrid: Fundación Germán Sánchez Ruipérez, 2008. ISBN 978-84-89384-31-6.

Dahlberg, I. (1979). Teoria da Classificação, ontem e hoje. Conferência Brasileira de Classificação Bibliográfica, Rio de Janeiro, 12-17 de setembro de 1972. Anais. Brasília, IBICT/ABDF, 1, 1979. 352-370.

Duranti, L. (1997). Diplomatica. Usos nuevos para una antigua ciencia. Córdoba: S. C., 1997. ISBN 9788492033256.

Esteban Navarro, M. A. (1995). La representación y la organización del conocimiento en los archivos: los lenguajes documentales ante los procesos de classificación, ordenación y descripción. // Marco, Francisco Javier García (ed.). Organización del conocimiento em sistemas de información y documentación. Zaragoza : Libreria General, 1995. 65-90.

Foskett, A. C. (1973). A abordagem temática da informação. Tradução de Antônio Agenor Briquet de Lemos. São Paulo: Polígono; Brasília: Ed.UnB, 1973.

Gomes, H. E. (1996). Classificação, tesauros e terminologia: fundamentos comuns. Palestra preparada para as Tertúlias do Departamento de Biblioteconomia da UNIRIO, jul. 1996.

Guimarães, J. A. C. (2003). A análise documentária no âmbito do tratamento da informação: elementos históricos e conceituais. // Rodrigues G. M.; Lopes, I. L. (org.). Organização e representação do conhecimento na perspectiva da Ciência da Informação. Brasília: Thesaurus, 2003. ISBN 8570623992. 100-118.

Héon, G. (1999). La classification. // Couture, C. Les fonctions de L'Archivistique contemporaine. Québec: Presses de L’Université du Québec, 1999. 219-254.

Heredia Hererra, A. (1991). Archivistica general. Teoria y practica. Sevilha: Diputación de Sevilla, 1991. ISBN 847798-056-X.

Höffe, O. (2008). Aristóteles. Tradução de Roberto Hofmeister Pich. Porto Alegre: Artmed, 2008. ISBN 978-85-3631459-4.

Hjorland, B. (2002). Domain analysis in information science: eleven approaches - traditional as well as innovative. // Journal of Documentation, 58 (2002). 422-462.

Kaula, P. N. (1984). Rethinking on the concepts in the study of classification (Repensando os conceitos no estudo de classificação). Herald of Library Science. 23:2, (Jan./Apr. 1984) 30-44.

Langridge, D. W. (1977). Classificação: abordagem para estudantes de biblioteconomia. Trad. Rosali P. Fernandez. Rio de Janeiro: Interciência, 1977.

Maltby, A. (1975). Sayers' Manual of classification for librarians. London: A. Deutsch / A Grafton Book, 1975.

Mills, J. (1960). A morden outline of library classification. London, Chapman and Hall, 1960.

Olson, H. A. (2011). A potência do não percebido: Hegel e Dewey no pensamento classificatório. // InCID: R. Ci. Inf. e Doc., Ribeirão Preto, 21 (jan./jun. 2011). 3-15.

Piedade, M. A. R. (1983). Introdução à teoria da classificação. 2. ed. Rio de Janeiro: Interciência, 1983.

Ranganathan, S. R. (1976). Colon classification. 6. ed., 4. reimpr. Bombay; Calcutta; New Delhi; Madras; Lucknow; Bangalore; London; New York: Asia Publishing House, 1976.

Ranganathan, S. R. (1967). Prolegomena to library classification. Bombay: Asia Publishing House, 1967. ISBN 9780210227312.

Rousseau, J.-Y.; Couture, C. (1998). Os fundamentos da disciplina arquivística. Lisboa: Dom Quixote, 1998. ISBN972-20-1428-5.

Sales, R. (2014). A organização da informação de Julius Kaiser: o nascimento do método analítico-sintético. Saarbrücken, Alemanha: Novas Edições Acadêmicas, 2014. ISBN978-3-639-61272-1.

Sayers, W. C. B. (1955). An introduction to library classification. 9. ed. Londres: Grafton, 1955. 
Schellenberg, T. R. (2002). Arquivos Modernos: princípios e técnicas. 6. Ed. Rio de Janeiro: FGV, 2002. ISBN 85-2250374-5.

Schreiner, H. B. (1979). Considerações históricas acerca do valor das classificações bibliográficas Conferência Brasileira de Classificação Bibliográfica, Rio de Janeiro, 1976. Anais..., 1. Rio de Janeiro, IBICT/ABDF, 1979. 190-207.

Silva, A. M. et al. (1999). Arquivística. Teoria e prática de uma ciência da informação. Porto: Afrontamento, 1999.

Sousa, R. T. B. (2007). A classificação como função matricial do que-fazer arquivístico. // Santos, B. dos S.; Innarelli, H. C.; Sousa, R. T. B. de (Org.). Arquivística: temas contemporâneos: classificação, preservação digital, gestão do conhecimento. Distrito Federal: SENAC, 2007. 79-172.
Sousa, R. T. B. (2006). Classificação de documentos arquivísticos: trajetoria de um conceito. Arquivística.net, Rio de Janeir., 2:2 (2006). 120-142.

Vickery, B. C. (1980). Classificação e indexação nas ciências. Rio de Janeiro BNG/ Brasilart, 1980.

Weigand, W. A. (1996). Irrepressible reformer: a biography os Melvil Dewey. Chicago e Londres: Amarican Library Association, 1996. ISBN 0-8389-0680-X.

Enviado: 2016-02-09. Segunda versión: 2016-04-26 Aceptado: 2013-04- 
